\title{
Solar PV System for Energy Conservation Incorporating an MPPT Based on Computational Intelligent Techniques Supplying Brushless DC Motor Drive
}

\author{
R. Anand1, Dr. S. Saravanan' \\ ${ }^{1}$ Department of EEE, Sri Krishna College of Technology, Coimbatore, India \\ ${ }^{2}$ Department of EEE, Muthayammal Engineering College, Rasipuram, India \\ Email: anandmeped@gmail.com,saravanan.nivi@gmail.com
}

Received 19 April 2016; accepted 26 April 2016; published 16 June 2016

Copyright (C) 2016 by authors and Scientific Research Publishing Inc.

This work is licensed under the Creative Commons Attribution International License (CC BY). http://creativecommons.org/licenses/by/4.0/

\section{(c) (7) Open Access}

\begin{abstract}
This paper proposes an effective Maximum Power Point Tracking (MPPT) controller being incorporated into a solar Photovoltaic system supplying a Brushless DC (BLDC) motor drive as the load. The MPPT controller makes use of a Genetic Assisted Radial Basis Function Neural Network based technique that includes a high step up Interleaved DC-DC converter. The BLDC motor combines a controller with a Proportional Integral (PI) speed control loop. MATLAB/Simulink has been used to construct the dynamic model and simulate the system. The solar Photovoltaic system uses Genetic Assisted-Radial Basis Function-Neural Network (GA-RBF-NN) where the output signal governs the DC-DC boost converters to accomplish the MPPT. This proposed GA-RBF-NN based MPPT controller produces an average power increase of $26.37 \%$ and faster response time.
\end{abstract}

Keywords

Photovoltaic, Genetic Algorithms, Neural Network, Brushless DC Motors and Maximum Power Point Tracking

\section{Introduction}

Nowadays, we face exponentially increasing demand of energy which inadvertently requires the use of non-renewable sources such as coal and natural gas. Since these sources are constrained, they have a tendency to become depleted and also contribute to environmental pollution to a large extent. Apart from the fundamental 
limitations of fossil fuel, ecological considerations in the manner of the greenhouse gases and global warming are the variant prominent forces associated with the promotion of renewable energy sources. Hence, the evident choice of a renewable energy source is one that is found in abundance, and provides security for future enlargement and growth. It is the energy harnessed from the sun. The sun is an enormous energy source. The earth receives an average of $1.8 \times 10^{11} \mathrm{MW}$ power from the sun which is infinitely larger than that consumed from the rest of the sources of energy combined.

Abundance of solar energy makes it the most sought after energy source that can be easily converted into electrical energy using Photovoltaic (PV) arrays. Standalone applications of PV energy are quite prevalent. Applications such as water pumping, household appliances, fans, electrification of rural areas where the availability of grid connection, air conditioning, etc. is yet to be implemented using PV electricity. In spite of several advantages like superior dynamic response, increased efficiency, ease of maintenance, better speed-torque characteristics and long operating life, it seems that less ample attention has been given to the feasibility of using PV systems to actuate Brushless DC (BLDC) motors. The performance of DC motors and AC induction type motors energised by PV sources has been analysed in the literature [1]. In this proposed method, the usage of BLDC motor yields the highest efficiency in comparison with all conventional motors, and also demonstrates lesser energy consumption where electric demand exists.

In order to achieve increased efficiency in PV system, it is important to match the PV generators with the load impedance optimally, such that the consistency is maintained during inclement weather thus obtaining maximum power generation. Such a technique to achieve maximum power while maintaining system stability is called Maximum Power Point Tracking (MPPT). To operate the PV system at maximum power output for varying levels of temperature and solar insolation, the BLDC motor is connected to a PV module through an MPPT controller. Different methods to realise MPPT have been considered in PV power applications [2] [3]-[5].

There is no need of any physical delineation of PV array for an Artificial Neural Network (ANN). In order to assess the optimal operating point of PV systems accurately, several Neural Network systems are developed. A PV system designed using a PC incorporated MPP tracker is developed by [1] [2] and it integrates a PV module with MPP tracker and a DC motor is studied in [6].

Study of solar array modelling, and MPP tracking, and analysis of Neural Network which is a multi-layer perceptron model NN, are analysed in [3]-[5]. Multi-layer perceptron NN (MLP) technique is normally premeditated in training [7]. However, it may not provide an optimal modelling due to the limitation of local minima during training, therefore, it could settle with a sub optimal solution. In this study, in addition to Levenberg Marquardt (LM) algorithm, Genetic assistance is provided to train the network which in turn optimizes the size of the hidden layer of Neural Network (NN) [8] the activation of which is established using the optimized distance between input vector and a target vector [9]. Rapidity over BP algorithm, exclusion of an encounter with the local minima problem, and also the more forceful and generous performance of the network in contrast with the GA-LM method mainly dealing with input data set are some of the high points considering the network.

This study aims to show that with the employment of a valuable MPPT controller [10], and the replacement of conventional motors like the brushed DC [6], sustainable energy in standalone PV system operating pumps can be accomplished [11]. The functional block diagram pertaining to the realised system is presented in Figure 1. An interleaved boost converter converts solar power into DC power [12]-[15], while the output of the MPPT controller activates the motor. The technique of GA-RBF-NN is incorporated into the controller that enables the system to minimize the Mean Square Error (MSE) and maximize sensitivity to inclement weather. The BLDC motor controller [16] senses the rotor position using Hall Effect sensors to generate corresponding switching signals for three phase AC powered inverters and to provide electronic commutation to the BLDC motor. A simple proportional integral (PI) control loop is incorporated into the speed controller. For establishing the expansive suitability of the system, it is of prime importance to match the supply and loads with the different phases of the day.

This proposed computational intelligent techniques based MPPT controller (GA-RBF-NN) produces an average power increase of $26.37 \%$ and faster response time when compared to the conventional method of GAMLP-NN. The rest of the paper is systematized as follows. Section 2 deliberates the Photovoltaic Array modelling. Section 3 briefly summarizes the operation and advantages of Interleaved DC-DC boost Converter [16]. Section 4 describes equivalent circuit of Brushless DC motor drive system and various significant parameters for speed control of the motor. On the basis of the above advantages concerned, we proposed Genetic AssistedRadial Basis Function-Neural Network structure of MPPT Controller in Section 5. Section 5 presents simulation 


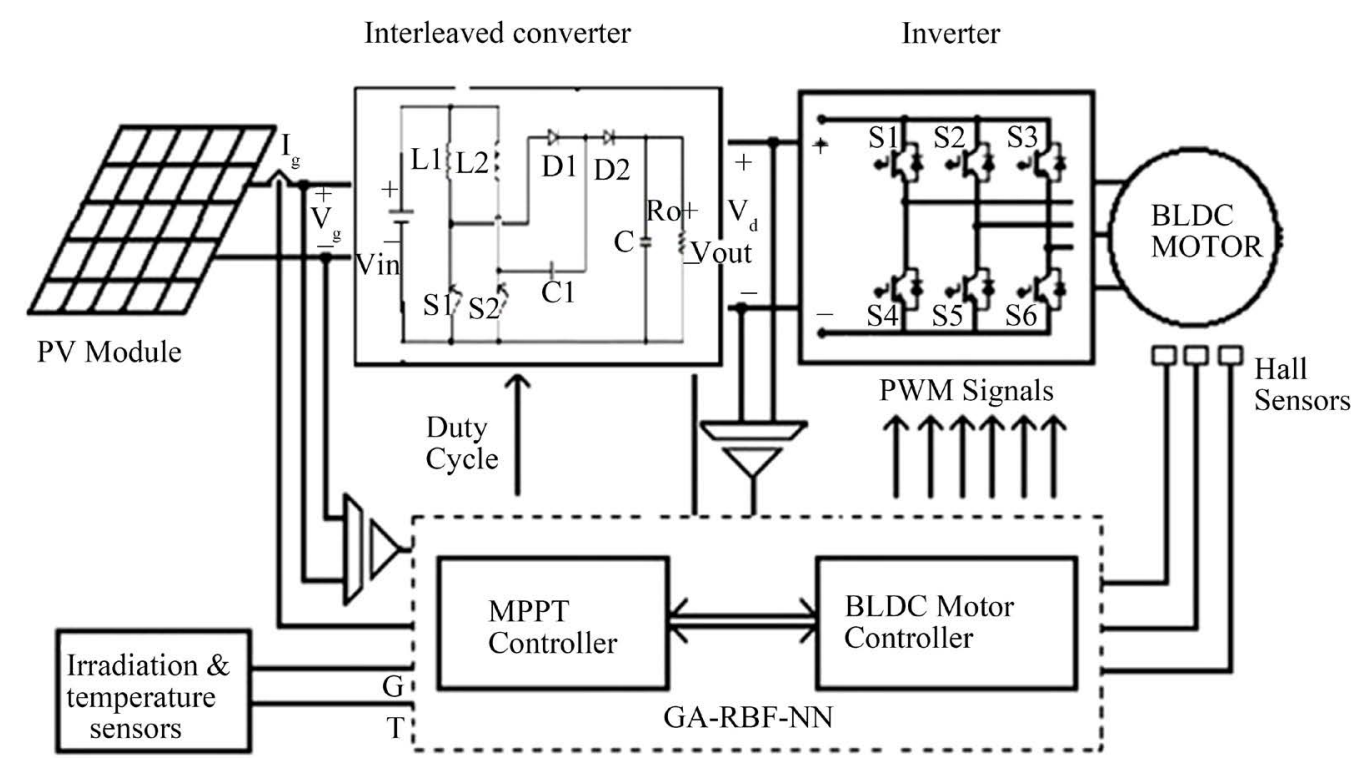

Figure 1. Block diagram of realised system.

results, number of competitive comparison analysis based on various numerical evaluations and Section 6 comprises the conclusions.

\section{PV Array Modelling}

Sunlight has an abundance of photons (i.e.) packets of energy. They contain tremendous amount of energy that varies in accordance with dissimilar light wavelength. Upon striking a cell and the PN junction device, these photons are either reflected or absorbed. If they get absorbed, a voltage appears across the junction that drives the DC current of the external circuit.

Figure 2 shows the equivalent circuit of a PV cell. Here the model has been exemplified by a current source connected anti-parallely with a diode, and the non-idealities are shown by inserting shunt $\left(R_{p}\right.$-parallel) and series resistances $\left(R_{s}\right)$. The simulation model of the Photovoltaic panel depends greatly on the output current $(I)$ of the $\mathrm{PV}$ equivalent model. Its mathematical equation is illustrated by,

$$
I=I_{p h}-I_{r}\left[\frac{e^{q}\left(V+I \cdot R_{a}\right)}{\eta^{k \cdot T}}-1\right]-\frac{V+I \cdot R_{s}}{R_{p}}
$$

where $V$ represents output voltage of $\mathrm{PV} ; q$ is the electrical charge, $\left(1.6 \times 10^{-19} \mathrm{C}\right) ; I_{p h}$ represents the photocurrent; $I_{r}$ represents reverse saturation current; $\eta$ is the quality factor of solar cell; $k$ is Boltzmann constant $\left(1.38 \times 10^{-23}\right) ; T$-temperature in Kelvin.

Figure 3 shows the V-I characteristics of a PV array

$$
I_{p h}=I_{r e f}\left[1+h t\left(T-T_{r e f}\right)\right] \times \frac{S}{S_{r e f}}
$$

where $I_{r e f}$ is short circuit current; $S$ is irradiance strength; $S_{\text {ref }}$ is reference irradiance strength; $T$ is temperature; $T_{r e f}$ is reference temperature and $h t$ is the cell module temperature coefficient. Power versus voltage characteristics for different irradiation level is shown in Figure 4. Equations (1) \& (2) can be enforced for the simulation of solar cell characteristics.

The PV Array must function at Maximum Power Point [17] [18]. Operation at a unique point with specified voltage and current values at a specific load resistance needs to be ensured. This requires a separate power converter for MPPT [19] [20] This system illustrates, an interleaved DC-DC converter utilized for impedance matching between load and PV module by altering the duty cycle of the power electronic switches, in order to extract maximum power. 


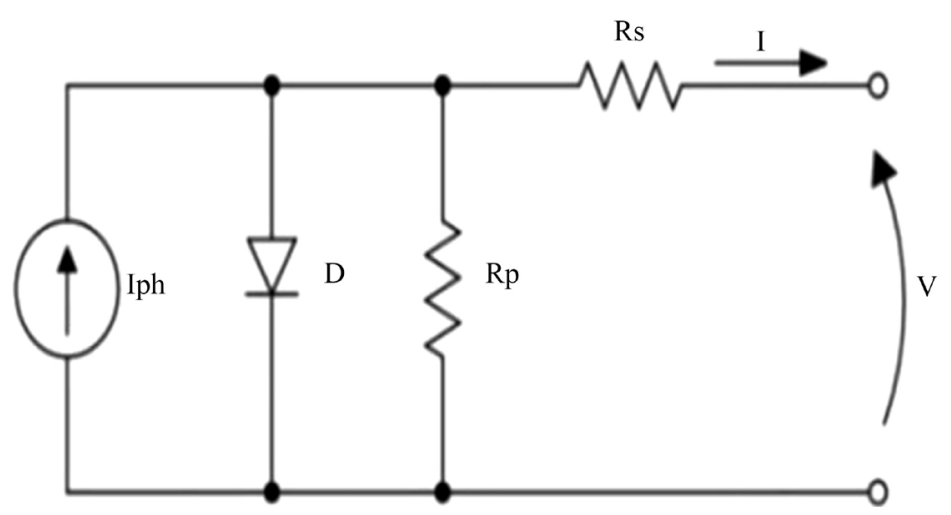

Figure 2. Equivalent circuit of PV array.

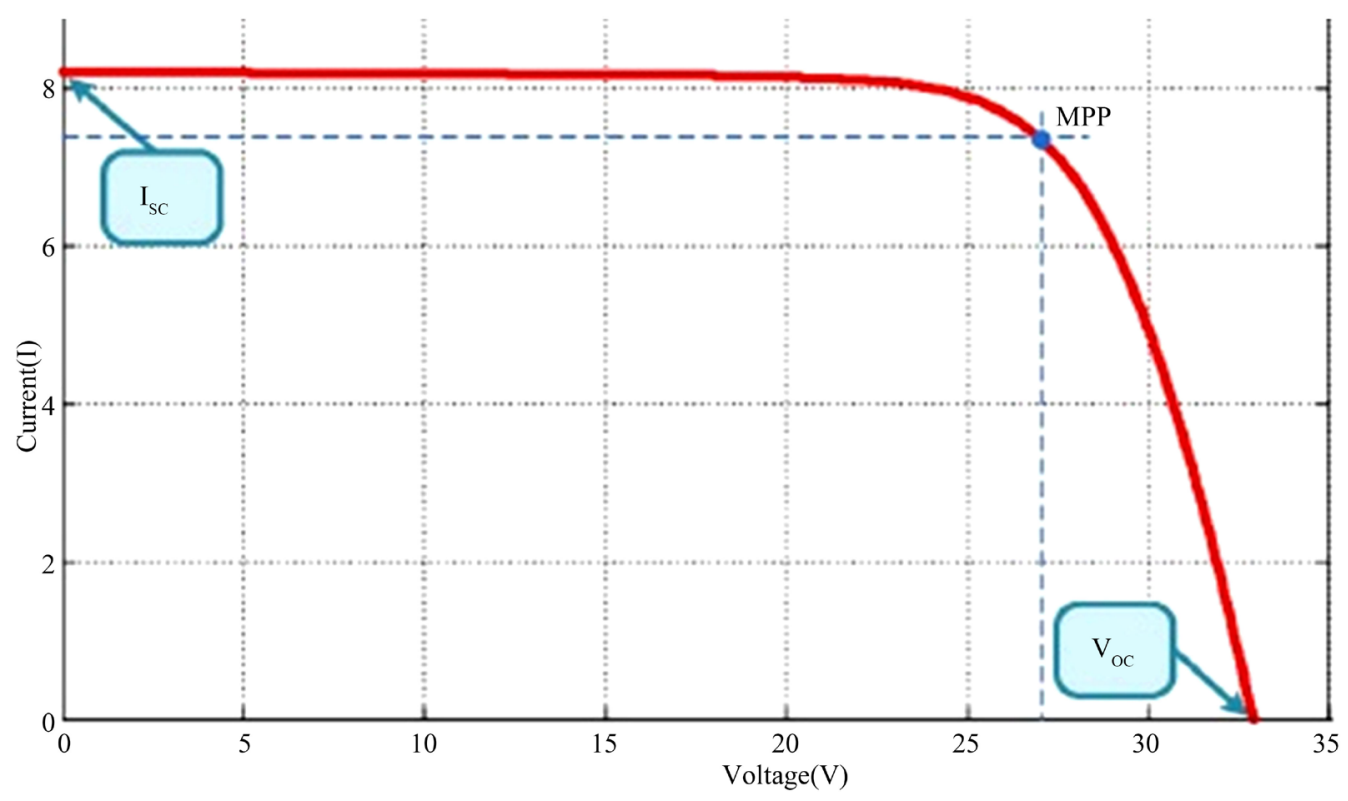

Figure 3. V-I characteristics of a PV array.

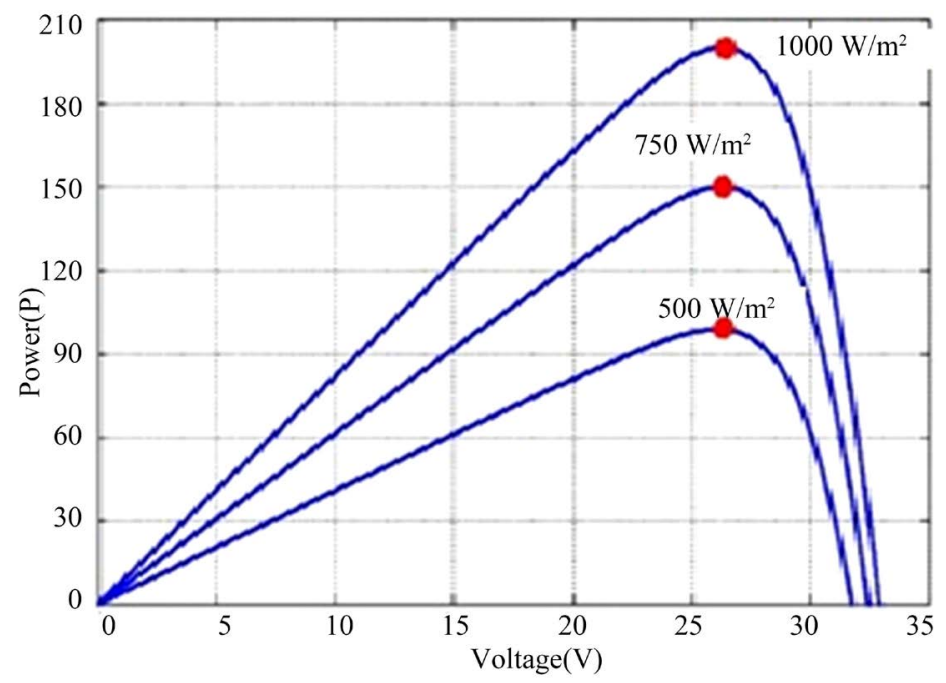

Figure 4. PV power characteristics for different irradiation level. 


\section{Interleaved DC-DC Boost Converter}

Interleaved Boost Converter (IBC) is mainly used for renewable energy sources. A number of boost converters connected in parallel are comprised of in an Interleaved Boost Converter that accommodates an equivalent frequency and phase shift. On average, conventional boost converters have been used to obtain higher output voltage. When these boost converters are operated for high ratios, they yield the result to high voltage and current stress on the switch [12]. Converters of this type have low values of conduction losses and input current ripple. They achieve high step-up voltage gain, which is mainly essential for non-conventional energy systems.

Here the operation of IBC is explained which is shown in Figure 5.

Figure 5 shows the circuit diagram of a two phase interleaved converter. The proposed interleaved converter consists of coupled conductors for enlarging the voltage gain, and a voltage lift capacitor offering an extra voltage conversion ratio. The efficiency is improved as large voltage spikes across main switches are interleaved. Therefore, reduced voltage stress requires the replacement of the low voltage rated power electronic switches for the reduction of conduction losses and to reduce cost. This converter is being characterized by a low ripple of input current thereby enabling the reduction of current stress. These advantages make the interleaved boost converter very attractive in the non-conventional energy sources like Solar PV systems.

In this circuit, primarily, when the switch $S_{1}$ is turned $\mathrm{ON}$, the current in the inductor $L_{1}$ increases linearly and $L_{1}$ stores energy. When the switch $S_{1}$ is turned OFF, diode $D_{1}$ conducts and that stored energy in the inductor begins to discharge, connecting the current to the load through the diode. After a half switching cycle of $S_{1}, S_{2}$ are also turned ON and OFF respectively in order to complete the same cycle of events. The boost ratio of interleaved converter is defined as,

$$
\frac{V_{d c}}{V_{\text {in }}}=\frac{1}{1-D}
$$

where $V_{d c}$ is the output voltage; $V_{i n}$ is the input voltage and $D$ is the duty ratio.

Figure 6 shows the transient and steady state response of Interleaved DC-DC boost converter with settling time of $0.01 \mathrm{~s}$. In comparison with a conventional boost converter the Interleaved DC-DC Boost converter has better performance characteristics due to its higher efficiency.

\section{BLDC Motor Drives}

A BLDC motor is a type of synchronous motor. This implies that the rotor has a permanent magnet rotating at the same frequency with the presence of a classic three phase stator like that of a synchronous motor.

For controlling the power electronic switches, the BLDC motors produce signals by accurately detecting the rotor position or magnetic pole position and hence are different from synchronous machines. Hall element is the most commonly used position sensor. However certain motors make use of optical sensors too. The variable

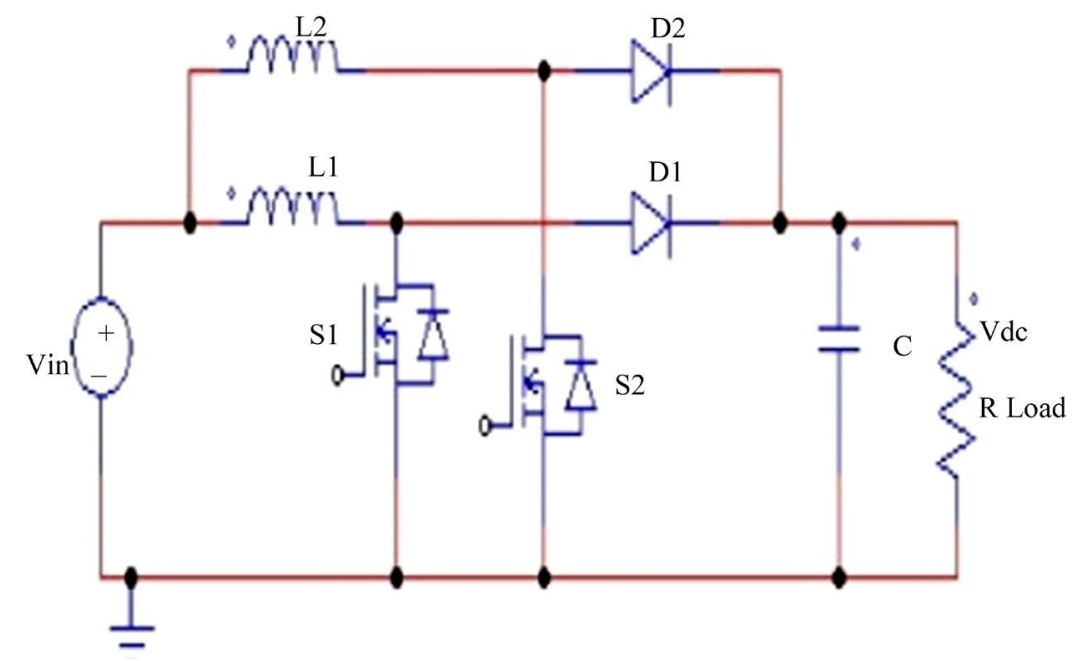

Figure 5. Two phases interleaved DC-DC boost converter. 
voltage and variable frequency (VVVF) that is usually necessary for a BLDC drive is provided by a three phase full bridge inverter as shown in Figure 7.

The PWM inverter with a six switch voltage source con Figuration and with constant DC link voltage $\left(V_{d c}\right)$, that is the same as permanent magnet synchronous motor and induction motor drives is developed. A BLDC motor can be represented by,

$$
\left[\begin{array}{l}
V_{a} \\
V_{b} \\
V_{c}
\end{array}\right]=\left[\begin{array}{lll}
R & 0 & 0 \\
0 & R & 0 \\
0 & 0 & R
\end{array}\right]\left[\begin{array}{c}
i_{a} \\
i_{b} \\
i_{c}
\end{array}\right]+\left[\begin{array}{ccc}
L-M & 0 & 0 \\
0 & L-M & 0 \\
0 & 0 & L-M
\end{array}\right] \frac{\mathrm{d}}{\mathrm{d} t}\left[\begin{array}{c}
i_{a} \\
i_{b} \\
i_{c}
\end{array}\right]+\left[\begin{array}{c}
e_{a} \\
e_{b} \\
e_{c}
\end{array}\right]
$$

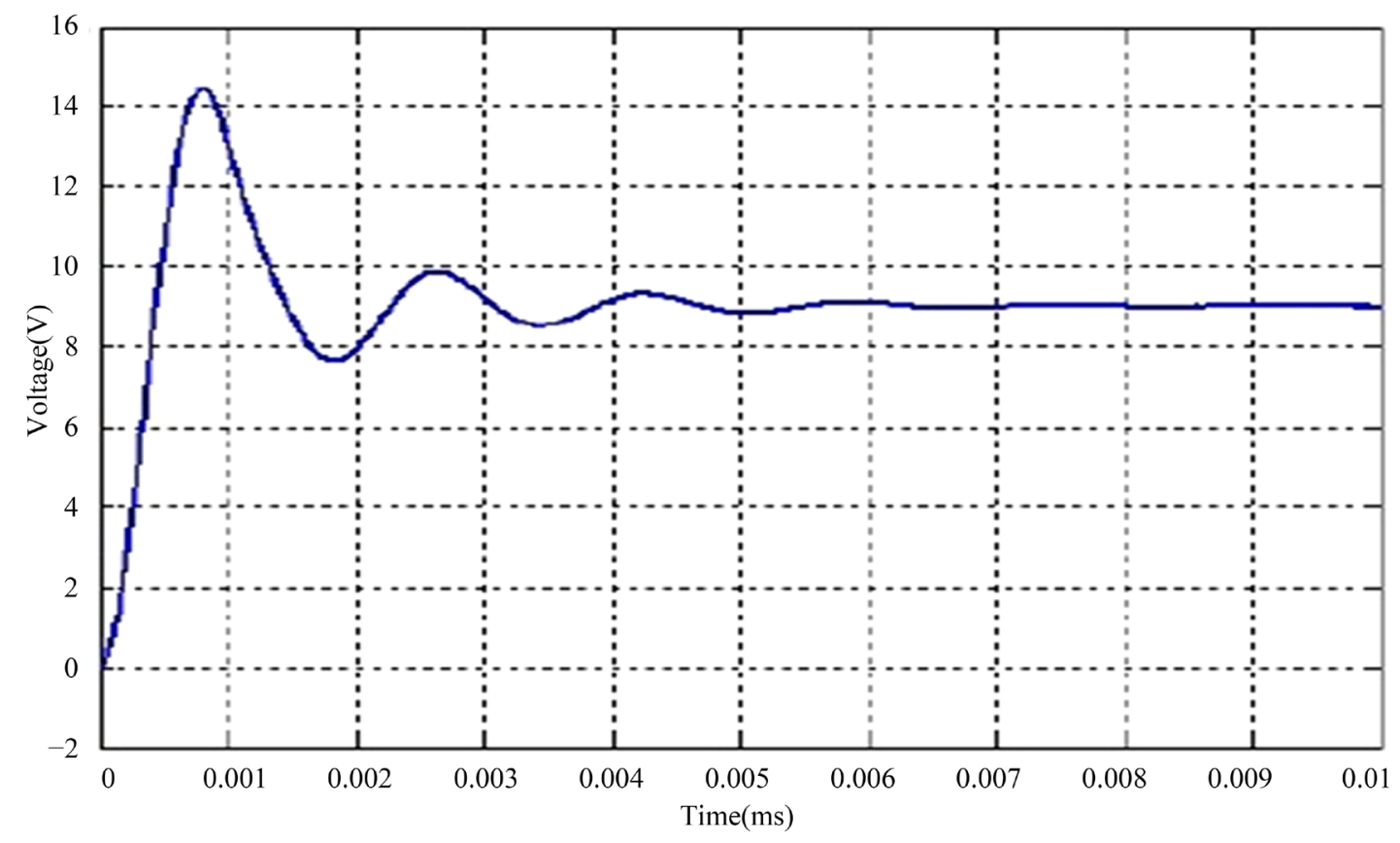

Figure 6. Transient and steady state response of Interleaved DC-DC boost converter.

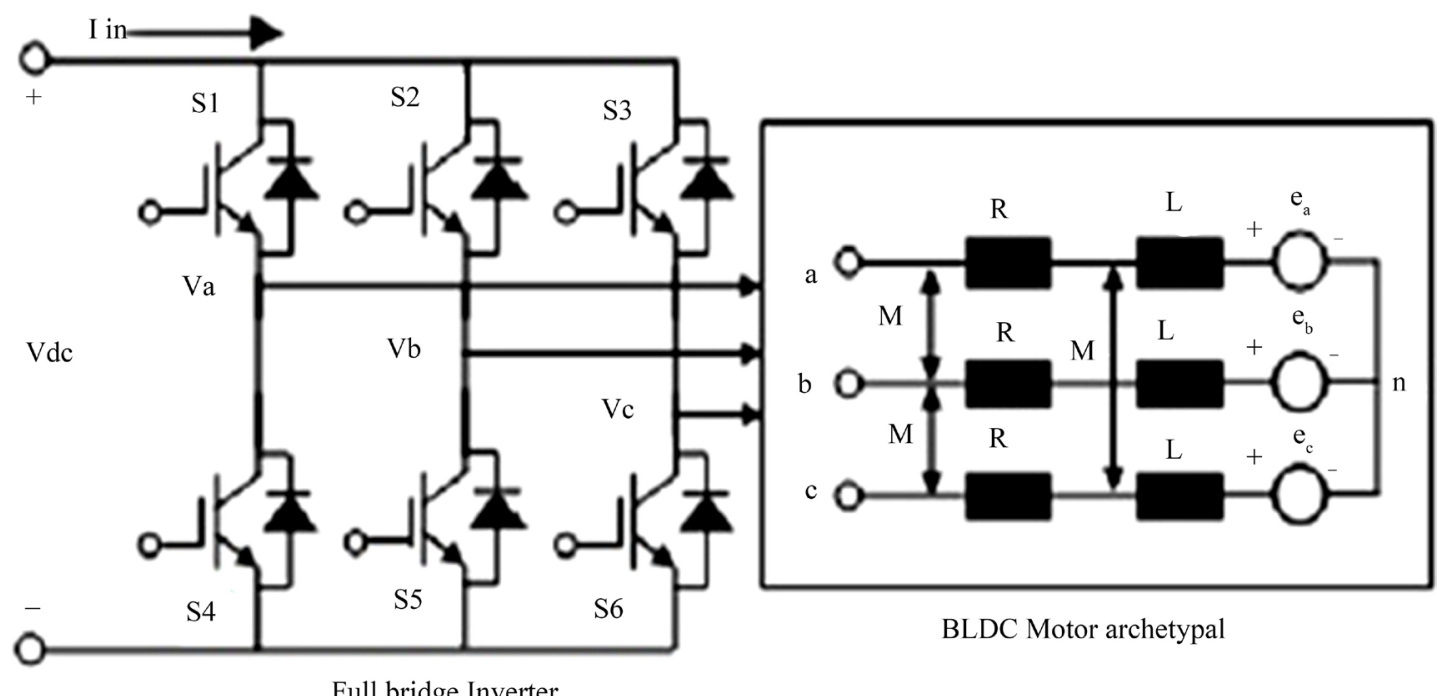

Full bridge Inverter 
where $V_{a}, V_{b}, V_{c}$ are represent the armature voltages; $i_{a}, i_{b}, i_{c}$ are the armature currents; $R$ is the resistance of the armature windings; $e_{a}, e_{b}, e_{c}$ are the back emf; $M \& L$ are the mutual-inductance and self inductance of the winding respectively.

$$
T_{e}=\left(e_{a} i_{a}+e_{b} i_{b}+e_{c} i_{c}\right) / w_{r}
$$

where $T_{e}$ represents the electromagnetic torque; $w_{r}$ represents the mechanical speed of Permanent Magnet rotor.

The equation representing a BLDC motor is,

$$
\frac{\mathrm{d} w_{r}}{\mathrm{~d} t}=\left(T_{e}-T_{L}-B w_{r}\right) / w_{r}
$$

where, $B$ is the damping constant; $T_{L}$ represents the load torque and $J$ represents the moment of inertia of the motor. The following Figure 8 illustrates the block diagram of a BLDC motor drive.

The system composed of a Proportional Integral (PI) speed controller \& limiter, Hall sensor, PWM controller, reference current generator, three phase bridge inverter and the load are realized. The PI speed controller controls the error by matching the speed of the motor with the reference value. Based on the controller and the position sensor the three phase reference currents are produced with the help of a reference current generator. The winding currents $\left(i_{a}, i_{b}, i_{c}\right)$ are controlled by the PWM controller in a small set about the reference currents. The motor currents and the reference currents are compared and switching pulses are generated accordingly to drive the three phase bridge inverter. Due to its simple arrangement and ease of implementation, the Proportional Integral controller is mostly utilized in electrical drive systems. The idealized equation of PI controller is,

$$
u(t)=k e(t)+\frac{1}{T_{i}} \int_{0}^{t} e(t) \cdot \mathrm{d} t
$$

where $k$ is the gain; $T_{i}$ is the integral time, and

$$
e(t)=r(t)-y(t)
$$

where $e(t)$ represents feedback error; $r(t) \& y(t)$ represents the input and output respectively. In terms of torque, the PI controller output value, is stated as

$$
T(n)=T(n-1)+K_{p}\{e(n)-e(n-1)\}+K_{I}\{e(n)\}
$$

where, $e(n-1)$ is the previous error value; $e(n)$ represents the current error signal; $K_{I}$ is the integral gain and $K_{p}$ is the proportional gain. From the equivalent circuit, the transfer function of speed in S domain of a BLDC motor can be derived as

$$
\frac{\theta}{V}=\frac{w}{V}=\frac{K_{t}}{2(R+L s)\left(b+J_{s}\right)+K_{t} K_{e}}
$$

where the rotating speed $(\theta=w)$ is the output and the input obtained is the Voltage $(V) ; R \& L$ are the winding resistances and inductance respectively; $b$ represents the damping factor; $J$ is the PM rotor inertia; $K_{t}$ represents the torque constant and $K_{e}$ represents motor constant. The efficiency of a BLDC motor is evidently higher when

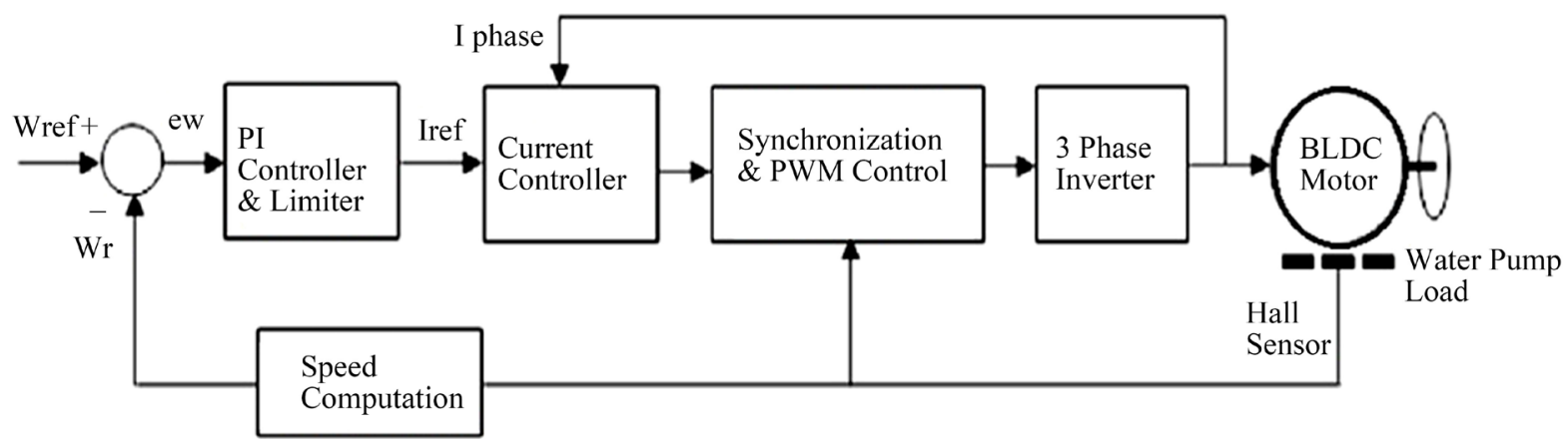


compared to that of a commutator motor of equal size. The absence of brush friction contributes to this regard. Since brushes are eliminated, it no longer necessitates maintenance. So, this BLDC motor is the best choice of pumping application for rural areas.

\section{GA-RBF-NN Structure of Mppt Controller}

There is no need for physical structuring of a solar array as long as an Artificial Neural Network (ANN) is concerned. For several decades, ANN technology has had a wide scope of endless possibilities in electrical power engineering field. In order to predict the optimal operating point of solar PV arrays, the development in ANN technology has led to the design of adaptive controllers. The most widely used technology to train a Multilayer Perceptron (MLP) is through Back Propagation (BP). But, it continues to suffer from limitations such as slow training. In the conventional method [1], due to the arrival at local minima, it leads to a sub optimal solution. Therefore modelling and fitting for a system may not be obtained from the results. The proposed technique describes a Radial Basis Function-Neural Network (RBF-NN). RBF network acts as a universal approximator and also retains good generalization properties. This configuration keeps the computation fairly economical. In this model, the distance between input and output vector determines the activation of the hidden unit. It has a strong tolerance to input noise which enhances the stability of system. In this paper, there is no risk of encountering local minima problem. One of the most popular and robust methods for reducing Mean Square Error (MSE) for higher order adaptive algorithms is the Levenberg-Marquardt (LM) method. RBF network yields a considerably better outcome in comparison to the other systems that utilize MLP networks trained by LM method. Genetic algorithm attributes to the optimization technique that replicates the exact process of natural evolution. The simulation of evolution of species is carried out through natural selection that optimizes the strategy for developing best individuals from the progenies. For selecting the number of hidden nodes, hidden layers and network patterns, Genetic Algorithms are used. Until the individual criterion is met, concepts such as inheritance, selection, crossover and mutation are proposed with the aim to find the finest solution to a problem. The GA creates a primary population and then appraises this population by teaching each chromosome a Neural Network. In the search for the finest network considerations, it then improves the population through manifold generations. In this, the number of hidden layers is optimized with the help of Genetic assistance. The RBF-NN is sufficiently trained using a hybrid genetic assisted LM algorithm. Since the algorithm can automatically adjust its network structure, the use of GA-RBF optimization algorithm can be seen as an adaptive system.

Fast and linear supervised methods are made use of in order to evaluate the weights from the hidden to the output layer. The V-I and P-V characteristics (Figure 3 \& Figure 4) of PV arrays are obtained by precisely training the network. The computational time for predicting the Maximum power point (MPP) is greatly reduced. The input, hidden and output are the three layers comprising the GA-RBF-NN network. Irradiation and temperature are the two dimensional vectors given to the input layer. Genetic assistance incorporated into the hidden layer elements recognizes the required number of hidden layers. The voltage (Vmp) and the load current (Imp) at the MPP are two of the output layers of the RBF-NN [21]. With the above described structure, a non-linear transformation from the input to hidden layer is obtained. However the hidden layer is connected to the output layer, hence it is linear due to the use of Gaussian functions for RBFs. The following Figure 9 shows the PV array of GA-RBF-NN Structure.

\section{Simulation and Experimental Results}

A computer code for RBF model is developed in the MATLAB software. The two Inputs for the proposed methods are Solar Insolation and Temperature. It does not need any physical definition of Solar Photovoltaic. Each RBF Networks has been trained until the best performance of Maximum Voltage Vmp and Maximum Current Imp (Maximum Power MP) is attained. The result of this proposed method guarantees the appropriateness of the input values considered. Each RBF Networks has been trained until the best performance is attained. If the criterion is met, then the optimal parameters, weights and hidden layer of the network are determined using Genetic algorithms (GAs), and it is used for testing and validating the GA-RBF-Network models. Table 1 shows the electrical parameters of the solar PV modules. Table 2 shows the parameters of BLDC Motor.

Simulation model of GA-RBF-NN model is shown in Figure 10. A silicon irradiance sensor has been utilized for varying levels of solar irradiation and temperature. Temperature tolerance is $25^{\circ} \mathrm{C} \pm 1.5^{\circ} \mathrm{C}$ [22]. In Figure 10 , the solar energy can converted into electrical energy by PV panels and it can match the load requirement by using 


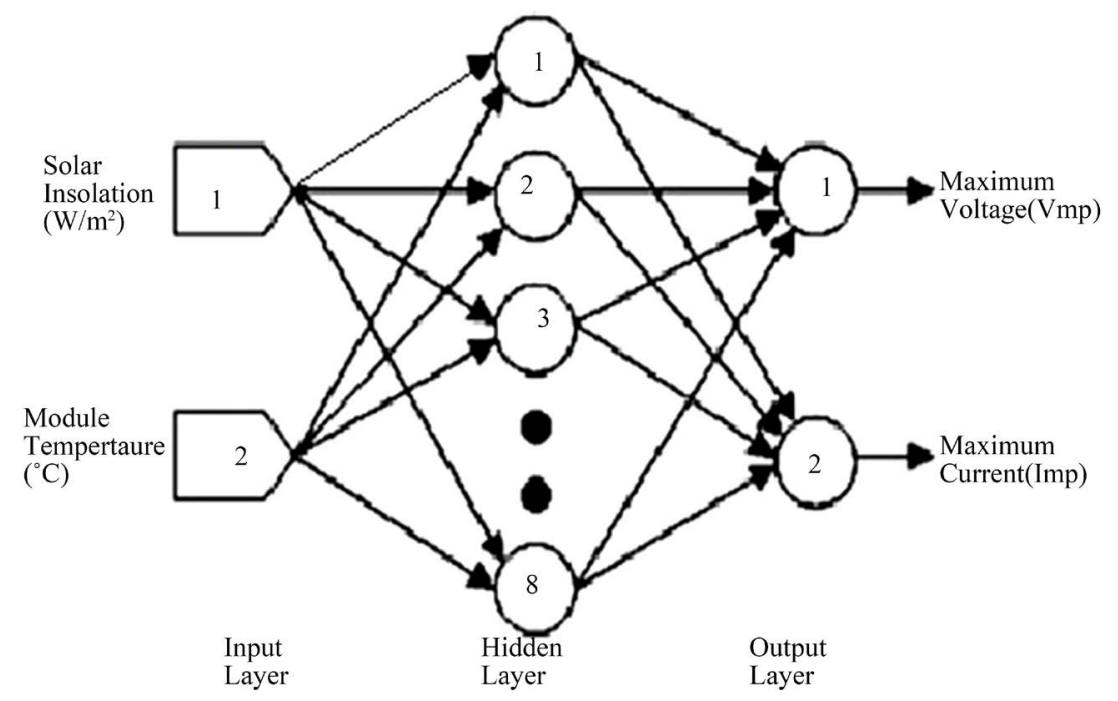

Figure 9. PV array GA-RBF-NN structure.

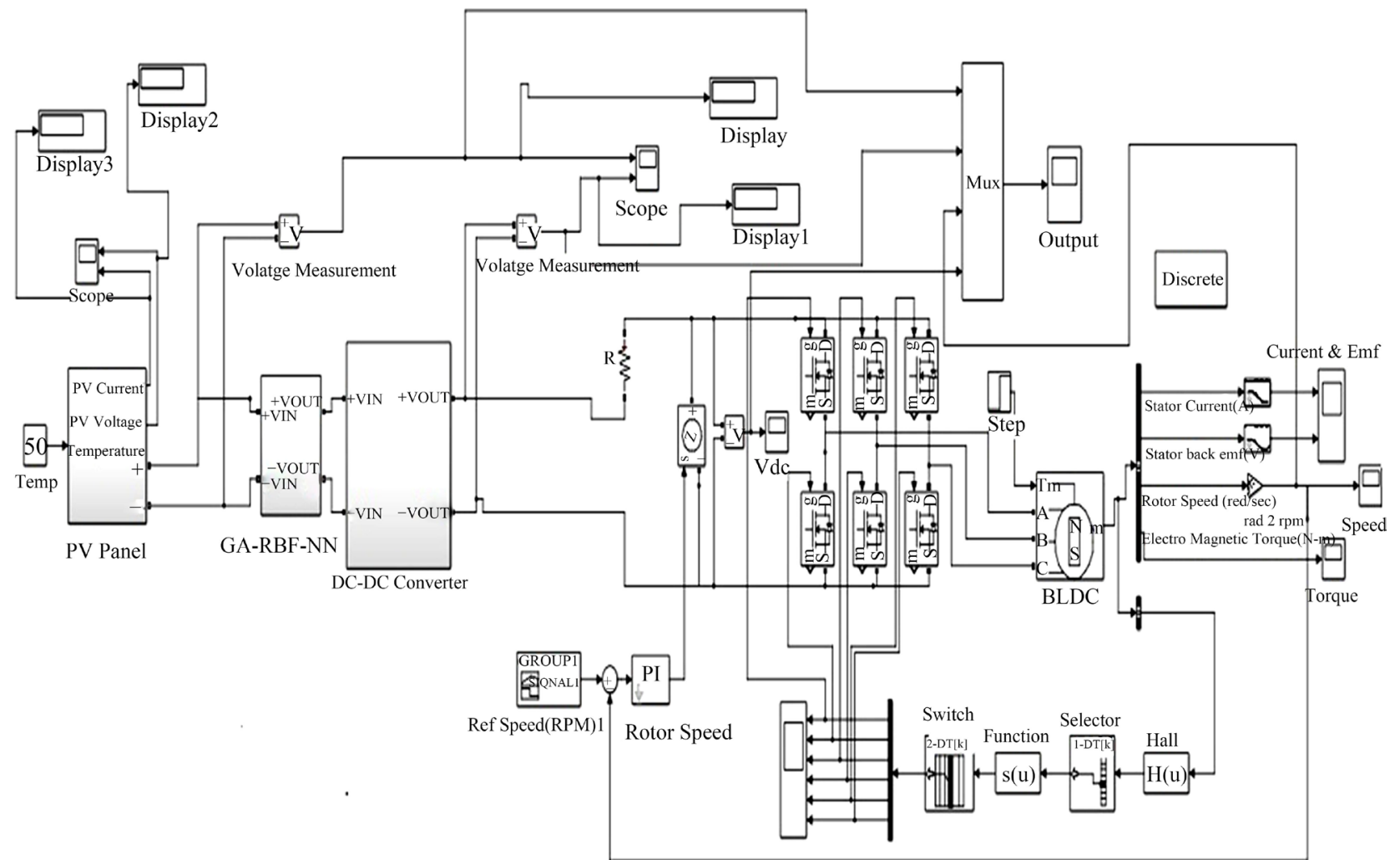

Figure 10. Simulation model of GA-RBF-NN- MPPT system.

proposed GA-RBF-NN based MPPT controller. Simulation model of interleaved DC-DC boost converter is shown in Figure 11. This converter comprises of coupled inductors for increasing the voltage gain and voltage spikes are of the switches are interleaved for getting reduced voltage stress. The specification of a BLDC motor is provided in Table 3. The developed GA-RBF-NN structure identifies the control signal required for the switching of Interleaved DC-DC boost converter and the realization of the controller [23].

To detect the number of hidden nodes residing within the hidden layers, Genetic assistance is given primarily to 


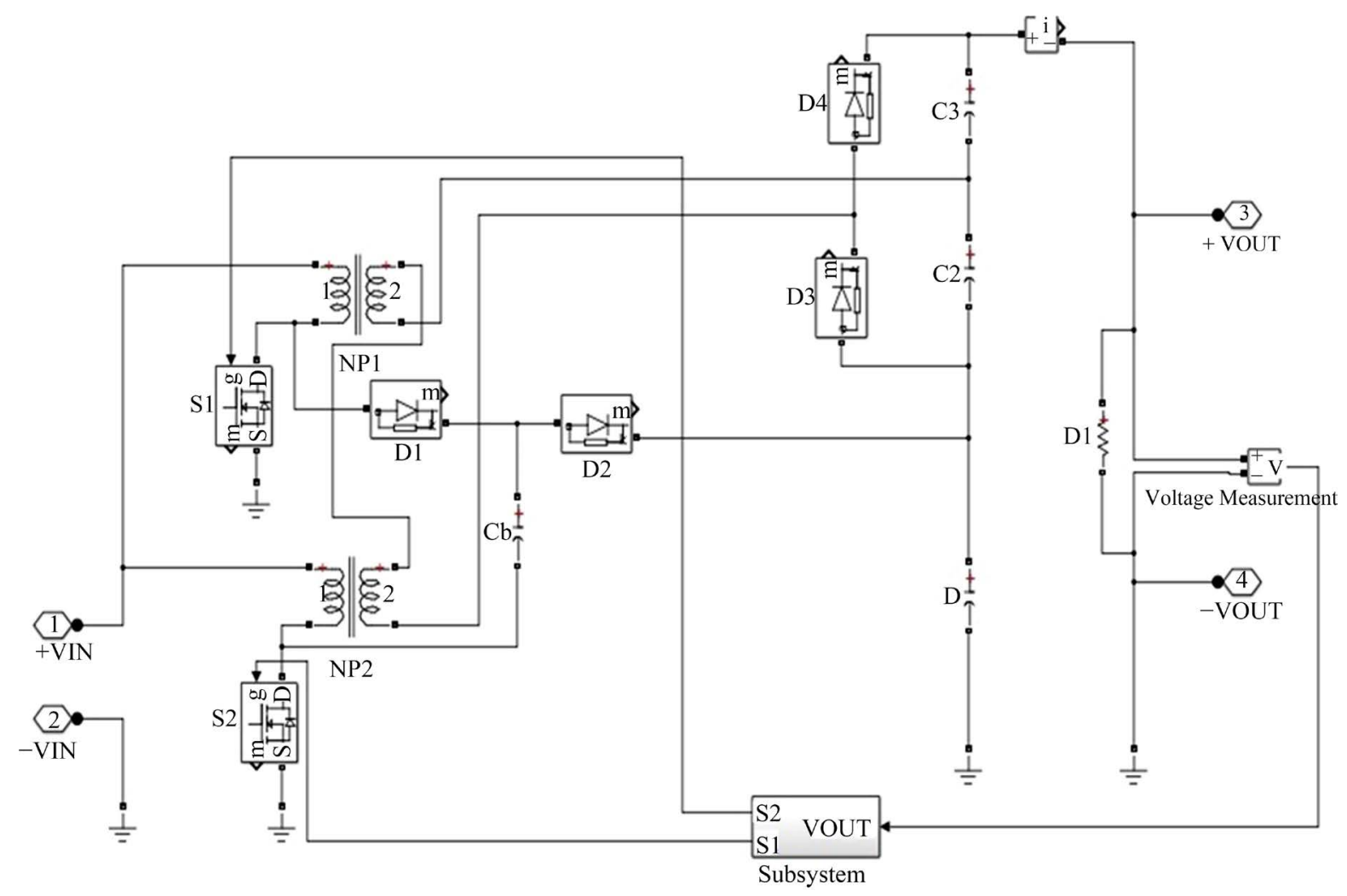

Figure 11. Simulation model of proposed interleaved boost converter.

Table 1. Electrical parameters of PV system.

\begin{tabular}{cc}
\hline Maximum Power & $P_{m}=200 W_{p}$ \\
Voltage at $M_{p p}$ & $V_{M p p}=27.1 \mathrm{~V}$ \\
Current at $M_{p p}$ & $I_{M p p}=7.82 \mathrm{~A}$ \\
Open Circuit voltage & $V_{O C}=32.9 \mathrm{~V}$ \\
Short circuit current & $I_{S C}=8.31 \mathrm{~A}$ \\
Temperature coefficient of $I_{S C}$ & $\propto=3.18 \times 10^{-3} \mathrm{~A} /{ }^{\circ} \mathrm{C}$ \\
\hline
\end{tabular}

Table 2. Parameters of BLDC motor.

\begin{tabular}{ccc}
\hline Parameters & Values & Units \\
\hline Number of poles $P$ & 8 & - \\
Nominal Voltage $V$ & 24 & Volts \\
Terminal Resistance phase to phase $R$ & 1.835 & $\mathrm{mH}$ \\
Inductance $L$ & 0.287 & $\mathrm{~V} /(\mathrm{rad} / \mathrm{sec})$ \\
Motor Constant $K_{e}$ & 0.0521 & $\mathrm{Kg} \mathrm{m} / \mathrm{A}$ \\
Torque constant $K_{t}$ & 0.0521 & $\mathrm{Kg} \cdot \mathrm{m}^{2}$ \\
PM rotor inertia $J$ & $19 \times 10^{-6}$ & \\
\hline
\end{tabular}

the RBF-NN which reduces the computation time. The GA constraints for training are $P_{m}=0.001, P_{C}=0.9$, Pop size $=25$, Selection basis $=$ Rank, Selection type $=$ Roulette, Progression $=$ Generational, Crossover $=$ one point, Maximum generation $=100$. The test results of Neural Networks trained using the four algorithms in 
Table 3. Apart from all these test results GA-RBF-LM algorithm is the best choice.

Since a network is most suitable for offline implementation in a MATLAB, a small network is developed by making use of eight neurons in the hidden layer which yields the optimized result. Training is given to this particular Neural Network (NN) methodology using four different algorithms such as Back propagation training using Delta Bar Delta (DBD) method, LM algorithm, GA-LM algorithms for MLP-NN and GA-LM algorithm for radial basis function networks thereby obtaining accuracy for each of the four above mentioned algorithms. Training of this network is done using equations generated randomly with 250 delta points (1) \& (2). The total number of iterations is 10 , and the goal is to achieve a minimised error of $1 \times 10^{-10}$. The activation of neurons is done by a hyperbolic function. Hidden layers and weight values attained by employing above four methods (DBD, LM algorithm, GA-MLP-LM and GA-RBF-LM) are made use of in order to evaluate the operation of the MPPT controller. Table 2 shows that the GA-RBF-LM algorithm provides the better results when compared to conventional method. For validating the MPPT, one other group of 60 random input-output data points were utilized. The mathematical model of error can be obtained and compared from maximum current, maximum voltage. Table 6 shows the supremacy of the evaluation of the proposed GA-RBF-LM algorithm. Comparison is done between power delivered or the Normal Operating Point (NOP), and the maximum power obtained by employing the proposed GA-RBF-NN MPPT controller. It shows that in the case of making use of the proposed MPPT controller, the Normal Operating Point is very much lesser than the power drawn by the load suggesting that at an average $25 \%-37 \%$ of power increase has been accomplished using the GA-RBF-NN controller. To analyze the PV system characteristics, the MATLAB simulation model of the system is developed and evaluated. The output waveforms are also analyzed to arrive at the suitable results. Table 4 gives the Comparison of Maximum power between GA-RBF-NN and RBF-NN. It shows the Genetic assisted RBF-NN with less number of errors in percentage. Table 5 shows that comparison results between GA-MLP-NN and GA-RBF-NN structures. It clearly

Table 3. The test results of neural networks trained using the four algorithms.

\begin{tabular}{|c|c|c|c|c|c|c|c|c|}
\hline & \multicolumn{2}{|c|}{$\begin{array}{c}\text { Back Propagation } \\
\text { algorithm with DBD } \\
\text { method }\end{array}$} & \multicolumn{2}{|c|}{ LM Algorithm } & \multicolumn{2}{|c|}{$\begin{array}{l}\text { GA-MLP-LM hybrid } \\
\text { algorithm }\end{array}$} & \multicolumn{2}{|c|}{ GA-RBF-LM algorithm } \\
\hline & $V_{m p}$ & $I_{m p}$ & $V_{m p}$ & $I_{m p}$ & $V_{m p}$ & $I_{m p}$ & $V_{m p}$ & $I_{m p}$ \\
\hline MSE & 0.0216220 & 0.0027955 & 0.0008322 & 0.0001280 & 0.0004287 & 0.0000311 & 0.0003897 & 0.0000216 \\
\hline $\begin{array}{l}\text { Normalized } \\
\text { MSE }\end{array}$ & 0.0196367 & 0.0019174 & 0.0007558 & 0.0000879 & 0.0003893 & 0.0000213 & 0.0001983 & 0.0000107 \\
\hline $\begin{array}{l}\text { Mean } \\
\text { absolute } \\
\text { error }\end{array}$ & 0.0982449 & 0.0334360 & 0.0171013 & 0.0088656 & 0.0096071 & 0.0041174 & 0.076218 & 0.0028132 \\
\hline $\begin{array}{l}\text { Max abs } \\
\text { error }\end{array}$ & 0.7178296 & 0.1992776 & 0.1665330 & 0.0268288 & 0.1377690 & 0.0118656 & 0.1124131 & 0.0106423 \\
\hline Min abs error & 0.0010255 & 0.0013521 & 0.0002858 & 0.0002419 & 0.0002270 & 0.0001434 & 0.0001892 & 0.0001072 \\
\hline
\end{tabular}

Table 4. Comparison of maximum power between GA-RBF-NN and RBF-NN.

\begin{tabular}{|c|c|c|c|c|c|c|c|}
\hline \multirow[t]{2}{*}{ Time (h) } & \multirow[t]{2}{*}{$\begin{array}{l}\text { Irradiation } \\
\left(\mathrm{mW} / \mathbf{c m}^{2}\right)\end{array}$} & \multirow[t]{2}{*}{ Temperature $\left({ }^{\circ} \mathrm{C}\right)$} & \multirow[t]{2}{*}{$\begin{array}{l}\text { Maximum } \\
\text { power, }(\mathbf{W})\end{array}$} & \multicolumn{2}{|c|}{$\begin{array}{c}\text { Results predicted by } \\
\text { GA-RBF-NN }\end{array}$} & \multicolumn{2}{|c|}{ Prediction results by $\mathrm{RBF}$} \\
\hline & & & & $\operatorname{Pmax}(\mathbf{W})$ & Error & $\operatorname{Pmax}(W)$ & Error \\
\hline $8-9$ & 55.267 & 29.170 & 5.142 & 4.838 & $5.91 \%$ & 4.843 & $5.81 \%$ \\
\hline $9-10$ & 76.213 & 31.394 & 6.405 & 6.368 & $0.58 \%$ & 6.350 & $0.85 \%$ \\
\hline $10-11$ & 90.950 & 32.930 & 7.257 & 7.288 & $0.44 \%$ & 7.372 & $1.60 \%$ \\
\hline $11-12$ & 96.900 & 34.967 & 7.926 & 7.910 & $0.21 \%$ & 8.066 & $1.76 \%$ \\
\hline $12-13$ & 95.703 & 35.884 & 8.101 & 8.088 & $0.16 \%$ & 8.250 & $1.85 \%$ \\
\hline $13-14$ & 86.797 & 36.524 & 7.849 & 7.922 & $0.94 \%$ & 8.034 & $2.36 \%$ \\
\hline $14-15$ & 70.299 & 37.176 & 7.065 & 6.946 & $1.68 \%$ & 6.975 & $1.28 \%$ \\
\hline $15-16$ & 49.329 & 37.002 & 5.518 & 4.974 & $9.86 \%$ & 4.989 & $9.60 \%$ \\
\hline
\end{tabular}


indicates that response time is faster in proposed method.The supremacy of the estimation of the proposed GA-RBF-LM hybrid algorithm is shown in Table 6. This table is signposted that minimized error in GA-RBFLM algorithm.

Figure 12 represents the variations of instantaneous PV Module output voltage of $30 \mathrm{~V}$. Figure 13 shows that the stator current $3 \mathrm{~A}$ and electromotive force of a BLDC is about $200 \mathrm{~V}$. Figure 14 shows that the electromagnetic torque of $6 \mathrm{~N}$-m. Figure 15 shows the rotor speed of about $3000 \mathrm{rpm}$ and Figure 16 represents Interleaved DC-DC boost converter with an output voltage of about $488 \mathrm{~V}$ obtained when it is connected to the water pump load.

Table 5. Comparison result.

\begin{tabular}{ccc}
\hline Constraints & GA-MLP-NN (Conventional Method) & GA-RBF-NN (Proposed method) \\
\hline Settling time $\quad T_{s}$ & $1.8 \mathrm{Sec}$ & $0.56 \mathrm{Sec}$ \\
Steady state error $e_{s s}$ & 0.136 & 0.086 \\
Undershoot period & 100 & 120 \\
\hline
\end{tabular}

Table 6. The test results of errors in maximum current and voltage by four different algorithms.

\begin{tabular}{ccccccccc}
\hline Error (\%) & $\begin{array}{c}\text { Back Propagation } \\
\text { algorithm with DBD } \\
\text { Method }\end{array}$ & \multicolumn{2}{c}{$\begin{array}{c}\text { LM } \\
\text { Algorithm }\end{array}$} & \multicolumn{2}{c}{$\begin{array}{c}\text { GA-MLP-LM hybrid } \\
\text { algorithm }\end{array}$} & $\begin{array}{c}\text { GA-RBF-LM } \\
\text { Algorithm }\end{array}$ \\
\cline { 2 - 3 } & $V_{m p}$ & $I_{m p}$ & $V_{m p}$ & $I_{m p}$ & $V_{m p}$ & $I_{m p}$ & $V_{m p}$ & $I_{m p}$ \\
\hline$<1$ & 6 & 25 & 32 & 45 & 55 & 68 & 61 & 72 \\
$1-10$ & 45 & 38 & 37 & 25 & 14 & 2 & 11 & 1 \\
$11-20$ & 14 & 7 & 1 & 0 & 1 & 0 & 0 & 0 \\
$21-30$ & 2 & 0 & 0 & 0 & 0 & 0 & 0 & 0 \\
$31-40$ & 1 & 0 & 0 & 0 & 0 & 0 & 0 & 0 \\
$41-50$ & 1 & 0 & 0 & 0 & 0 & 0 & 0 & 0 \\
$51-100$ & 1 & 0 & 0 & 0 & 0 & 0 & 0 & 0 \\
\hline
\end{tabular}

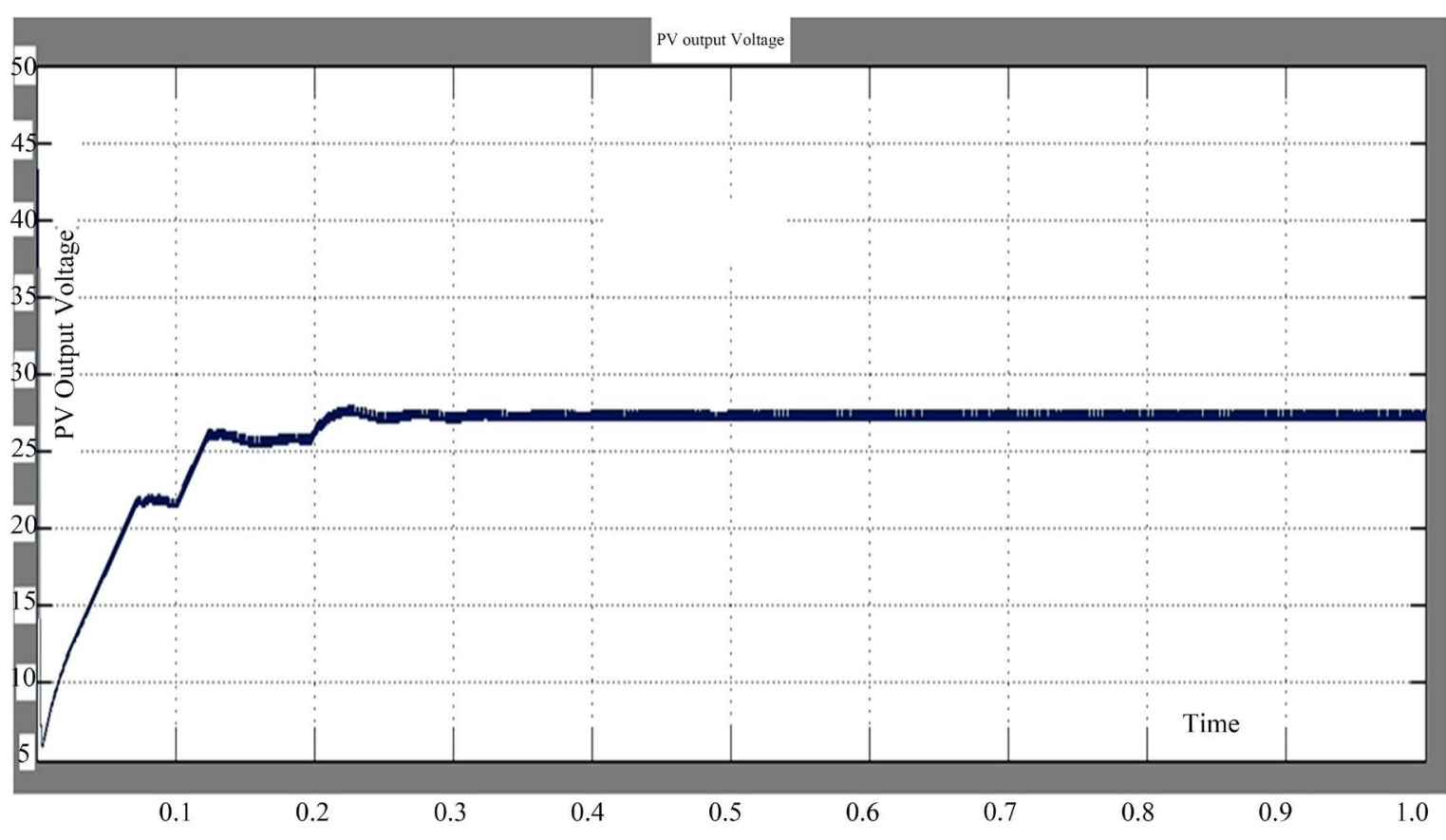

Figure 12. Result of PV output voltage vs time. 


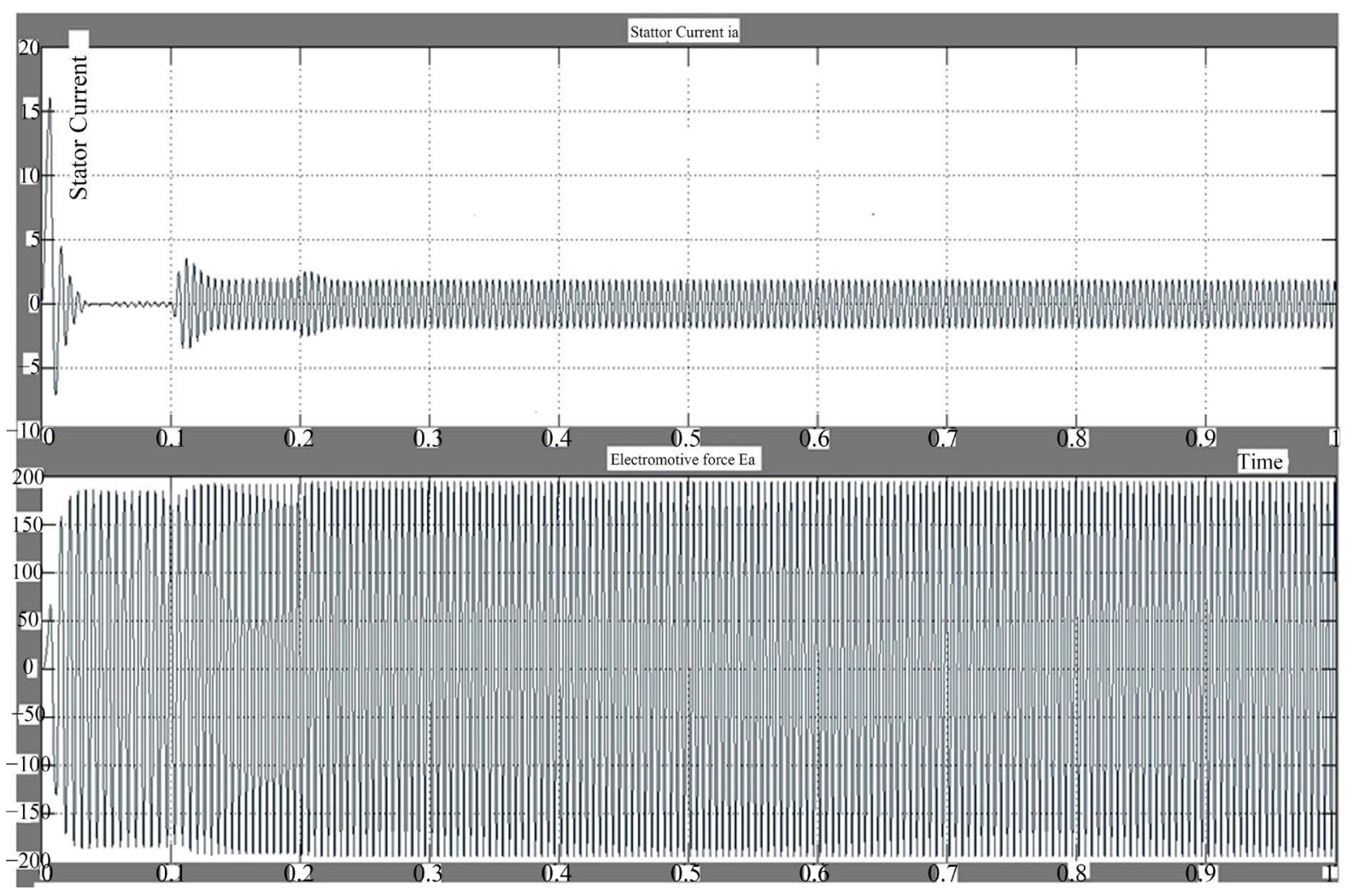

Figure 13. Stator current and electromotive force vs time.

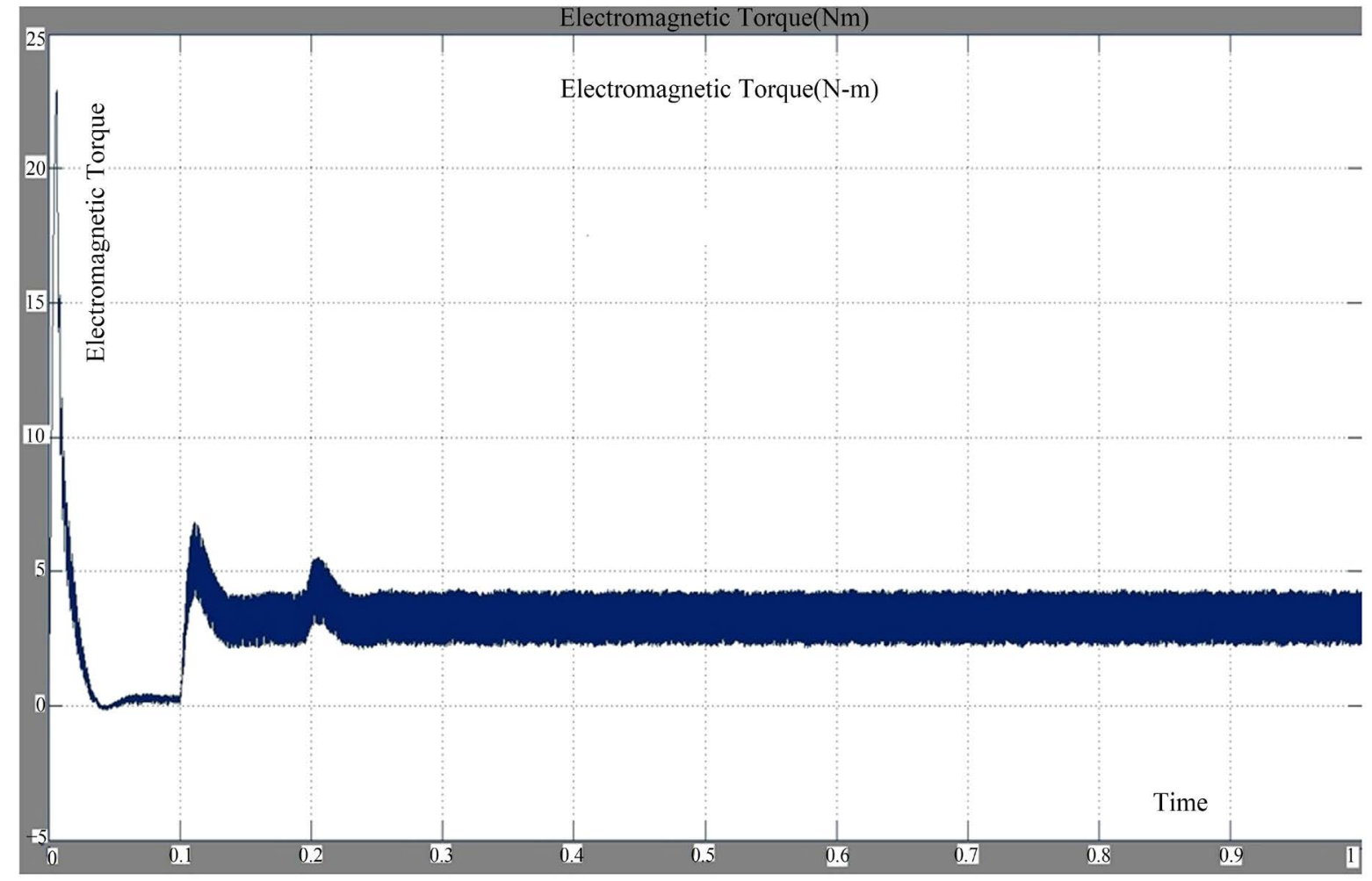

Figure 14. Electromagnetic torque vs time. 


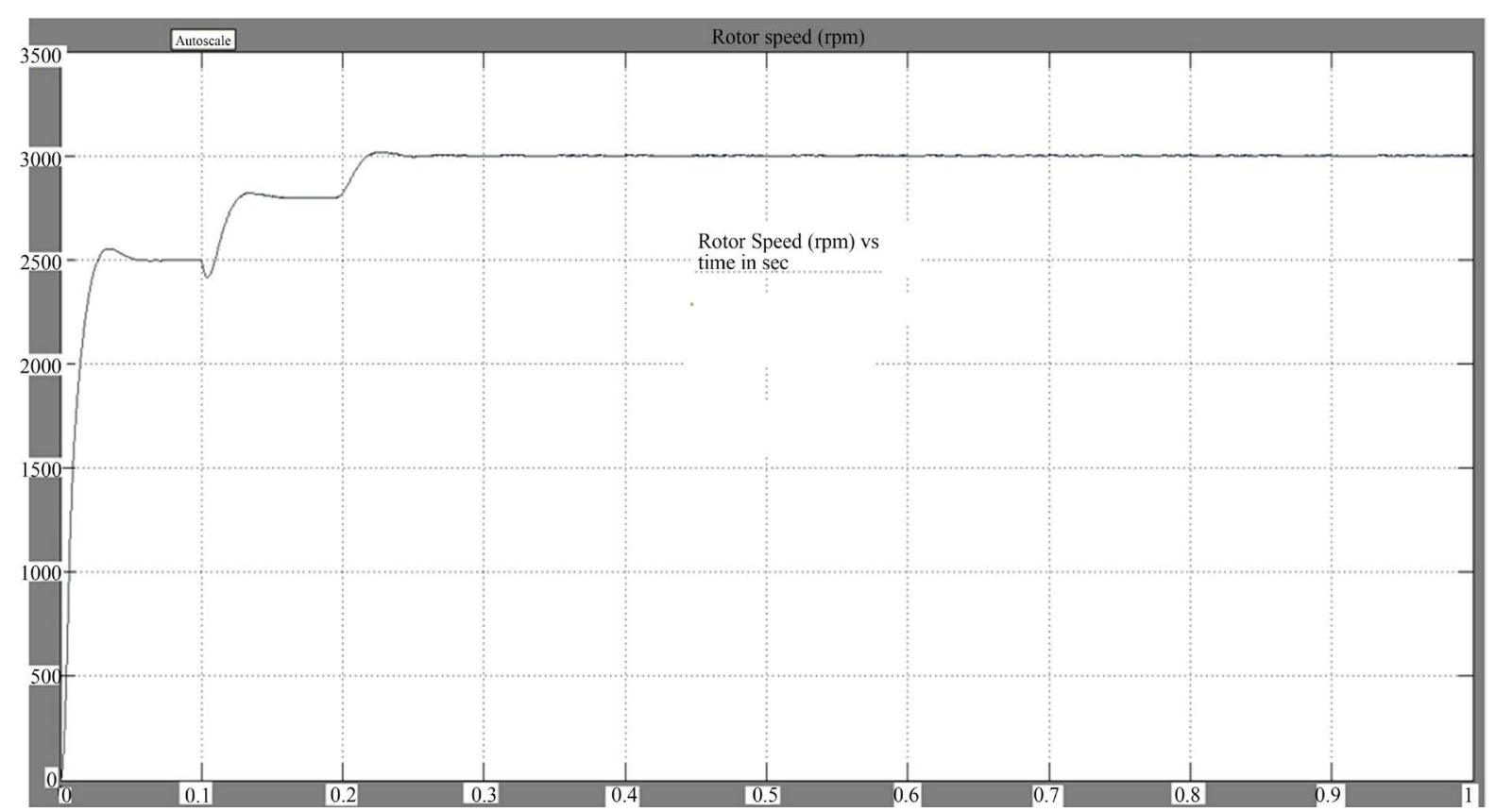

Figure 15. Rotor speed vs time.

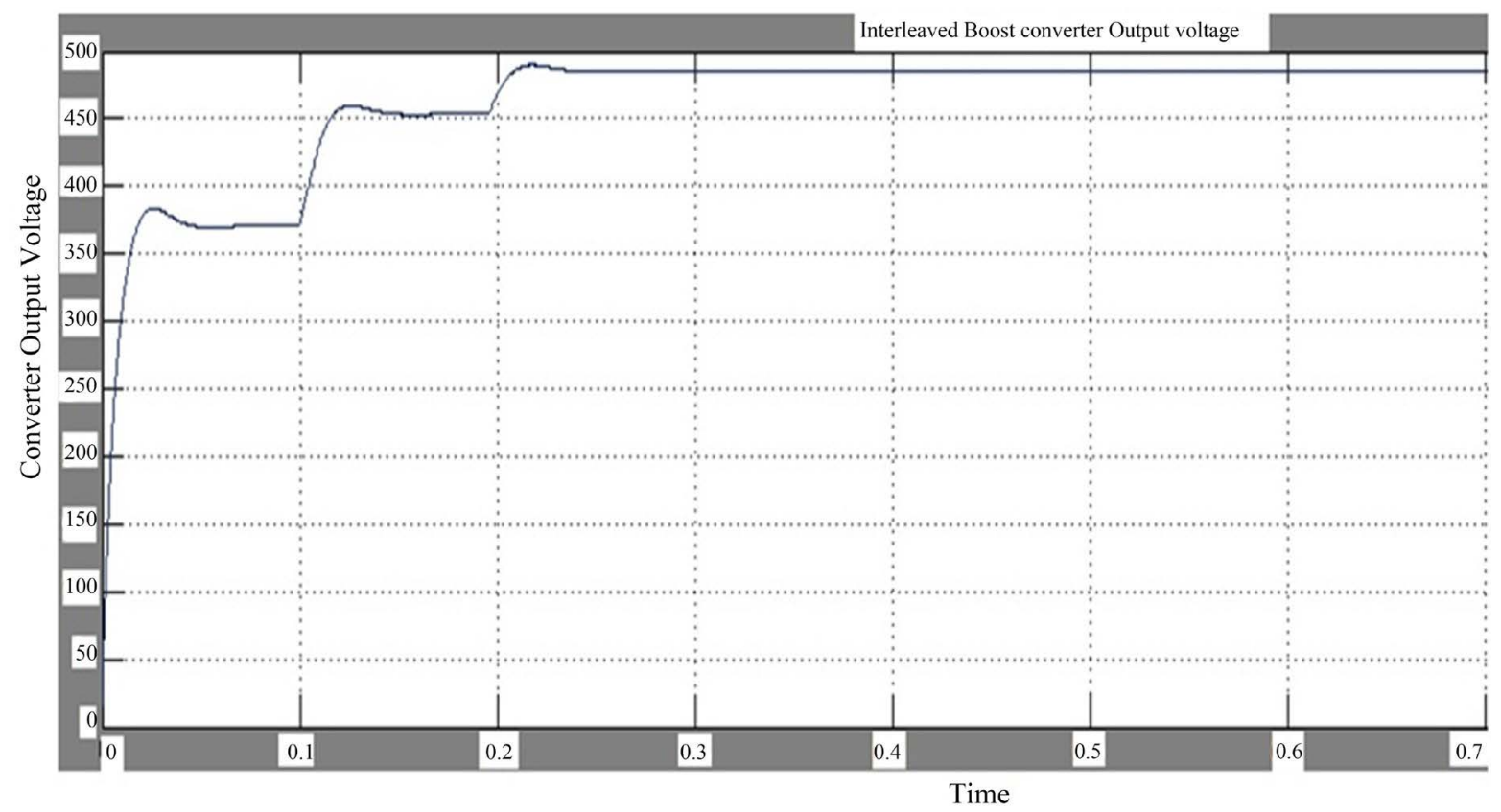

Figure 16. Interleaved boost converter output voltage vs time.

Figure 17 shows that experimental results of PV module, Voltage in $5 \mathrm{~V}$ olts/division, Current 5 Amps/ division and Time 1 second/division. Figure 18 shows that implementaion of hardware electrical characterstics (Phase to Phase Voltage and Current) for BLDC motor. Figure 19 shows that various rotor speed of BLDC motor for getting various step changes due to insolation.

This proposed technique offers following the advantages.

1) Acquisition and Updating Computational Times required in the Search for Voltage and Current output is low i.e., 0.56 Seconds of the proposed GA-RBF_NN technique, when compared with the Multilayer perceptron neural network. 


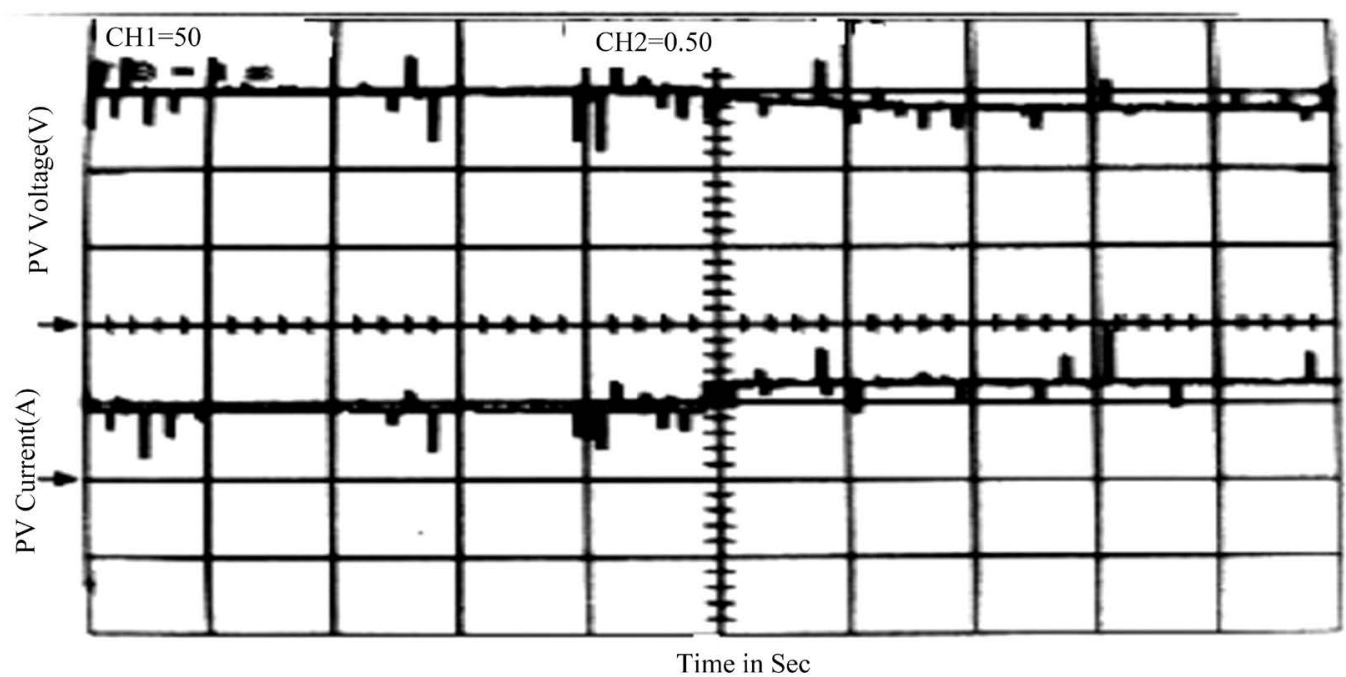

Figure 17. Output voltage and current waveform of photovoltaic module.

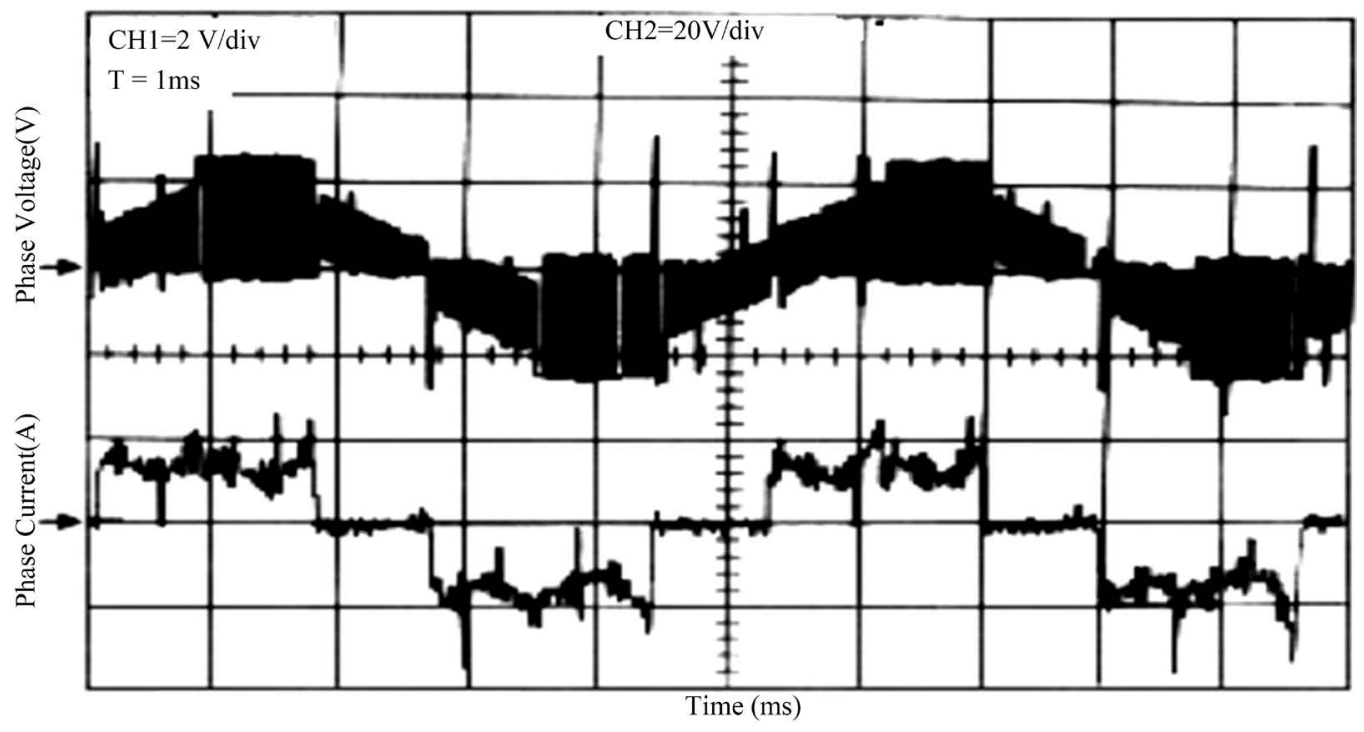

Figure 18. Voltage and current waveform for output of BLDC motor.

2) Due to Radial Basis Function network, the performance of the proposed algorithm under any load changes does not affect system parameters. The training of the network starts with the hidden layer using unsupervised learning algorithm and it is carried out till the output layer but with a supervised learning algorithm. Meanwhile, for the fine tuning of the network vector and the sudden variations in input vectors such as temperature and solar irradiation, supervised learning algorithm can be employed to both hidden unit and output layer.

In order to maintain the good dynamic response, the algorithm can be adjusted or modified due to the changing duty cycle of Interleaved DC-DC boost converter and Pulse width Modulation signals for inverters. So, it provides the best estimates of Maximum voltage and Maximum Current $\left(V_{m} \& I_{m}\right)$ for this system. Figure 20 shows the Interleaved converter.

\section{Conclusions}

The simulation model of an MPPT controller incorporating GA-RBF-NN and three phase BLDC drive is developed using MATLAB/Simulink. The results show that voltage and power can be well controlled. Hence, the proposed methodology provides an average increase of $26.37 \%$ of power and settling time is 0.56 sec. Genetic 


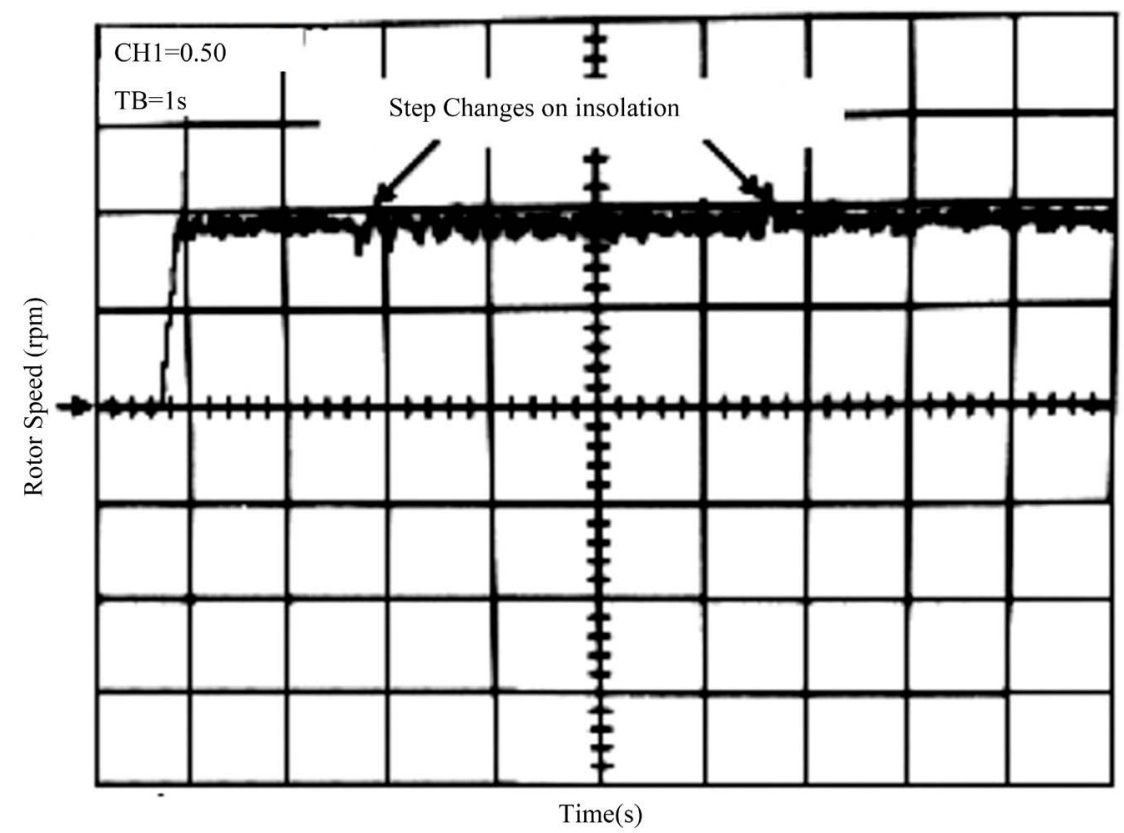

Figure 19. Mechanical characteristics of BLDC motor (Speed) for step changes due to insolation.
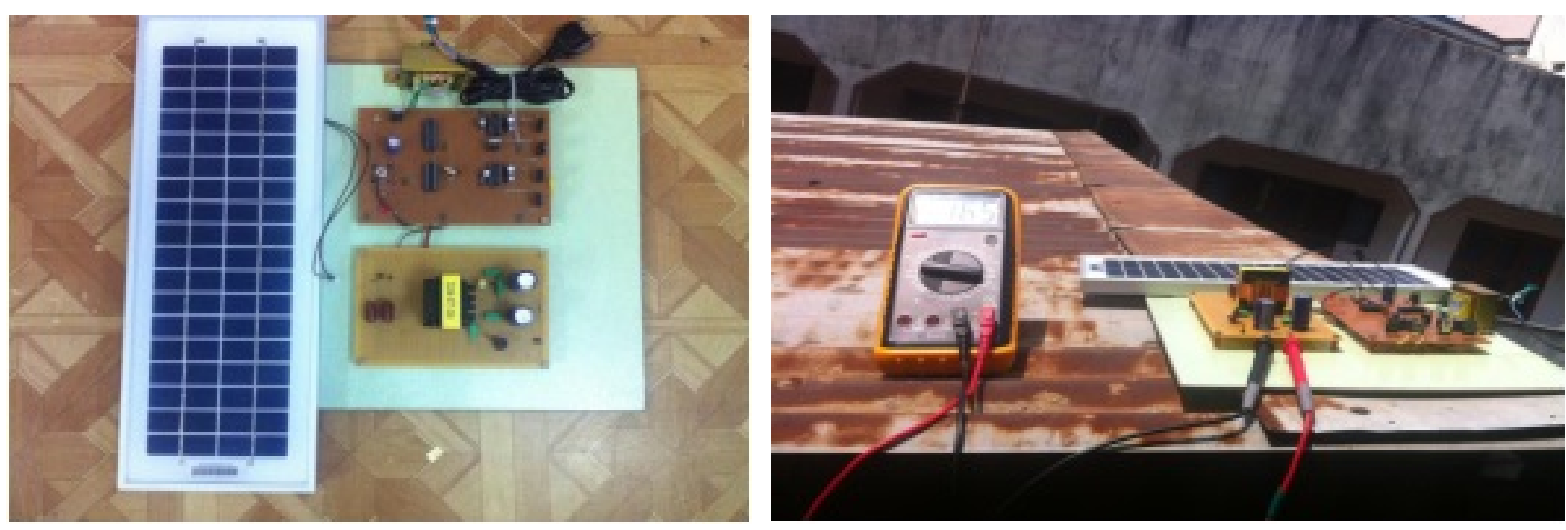

Figure 20. Hardware setup for interleaved DC-DC boost converter.

assistance has enabled the optimization of hidden nodes and also the size of the layers of the network. The GA-RBF-NN is trained faster than MLP which minimizes the possibility of convergence to local minima. The trained networks with GA-RBF-NN algorithm presented better results in the representation of the I-V and P-V characteristics of PV arrays requiring reduced computational time to predict the MPP in comparison to conventional models like GA-MLP-NN.

High step up conversion being the ultimate result is achieved by the superior performance of the interleaved DC-DC boost converter. This converter providing high step up gain is primarily utilized in non conventional energy sources like a PV system. Another paramount feature is their reduced voltage stress that is significantly lower compared to the output voltage. Other advantages of this converter include low ripple content of input current and reduced conduction losses, hence, it enhances the life time of the input sources.

The proposed BLDC drive system has been successfully implemented on a water pump. It shows that a six step PWM inverter drive controlled using PI (Proportional-Integral) control loop is able to control the speedtorque characteristics of BLDC motor smoothly. The results show that the proposed GA-RBF-NN model leads to the saving of energy since it can evaluate the MPPs accurately. The interleaved converter enabled with the proposed methodology as well as the PI controller of the BLDC motor drive in PV systems can be credibly implemented in rural areas where there is difficulty in grid connection. In the future, enhancement of this proposed 
method will be implemented in automatic water pumping system for agricultural area.

\section{References}

[1] Akkaya, R., Kulaksı, A.A. and Du, A. (2007) DSP Implementation of a PV System with GA-MLP-NN Based MPPT Controller Supplying BLDC Motor Drive. Energy Conversion and Management, 48, 210-218. http://dx.doi.org/10.1016/j.enconman.2006.04.022

[2] Zhang, L. and Bai, Y.F. (2005) Genetic Algorithm-Trained Radial Basis Function Neural Networks for Modelling Photovoltaic Panels. Engineering Applications of Artificial Intelligence, 18, 833-844. http://dx.doi.org/10.1016/i.engappai.2005.02.004

[3] Lin, W.-M., Hong, C.-M. and Chen, C.-H. (2011) Neural-Network-Based MPPT Control of a Standalone Hybrid Power Generation System. IEEE Transactions on Power Electronics, 26, 3571-3581. http://dx.doi.org/10.1109/TPEL.2011.2161775

[4] Koutroulis, E., Kalaitzakis, K. and Voulgaris, N.C. (2001) Development of a Microcontroller-Based Photovoltaic Maximum Power Point Tracking Control System. IEEE Transactions on Power Electronics, 16, 46-54. http://dx.doi.org/10.1109/63.903988

[5] Sharaf, A.M., AboulNaga, M.M. and El Diasty, R. (2000) Building-Integrated Solar Photovoltaic Systems-A Hybrid Solar Cooled Ventilation Technique for Hot Climate Applications. Renew Energy, 19, 91-96. http://dx.doi.org/10.1016/S0960-1481(99)00021-X

[6] Appelbaum, J. (1986) Starting and Steady-State Characteristics of DC Motors Powered by Solar Cell Generators. IEEE Transactions on Energy Conversion, 1, 17-24. http://dx.doi.org/10.1109/TEC.1986.4765665

[7] Kim, Y., Jo, H. and Kim, D. (1996) A New Peak Power Tracker for Cost-Effective Photovoltaic Power Systems. IEEE Proceedings of Energy Conversion Engineering Conference (IECEC), 3, 1673-1678.

[8] Al-Amoudi, A. and Zhang, L. (2000) Application of Radial Basis Function Networks for Solar-Array Modeling and Maximum Power Point Prediction. IEE Proceedings_-Generation, Transmission and Distribution, 147, 310-316. http://dx.doi.org/10.1049/ip-gtd:20000605

[9] Paul, S. and Thomas, J. (2014) Comparison of MPPT Using GA Optimized ANN Employing PI Controller for Solar PV System with MPPT Using Incremental Conductance. 2014 International Conference on IEEE Power Signals Control and Computations (EPSCICON), Thrissur, 6-11 January 2014, 1-5. http://dx.doi.org/10.1109/epscicon.2014.6887518

[10] Latham, A.M., Pilawa-Podgurski, R., Odame, K.M. and Sullivan, C.R. (2013) Analysis and Optimization of Maximum Power Point Tracking Algorithms in the Presence of Noise. IEEE Transactions on Power Electronics, 28, 3479-3494.

[11] Oi, A. (2005) Design and Simulation of Photovoltaic Water Pumping System. In: Electrical Engineering, Master of Science in Electrical Engineering, California Polytechnic State University, San Luis Obispo, 113.

[12] Zhu, L., Wang, K.R., Lee, F.C. and Lai, J.S. (2003) New Start-Up Schemes for Isolated Full-Bridge Boost Converters. IEEE Transactions on Power Electronics, 18, 946-951. http://dx.doi.org/10.1109/TPEL.2003.813758

[13] Yao, G., Chen, A. and He, X. (2007) Soft Switching Circuit for Interleaved Boost Converters. IEEE Transactions on Power Electronics, 22, 80-86. http://dx.doi.org/10.1109/TPEL.2006.886649

[14] Carrasco, J.M., Franquelo, L.G., Bialasiewicz, J.T., Galvan, E., Portillo Guisad, R.C., Prats, M.A.M., Leon, J.I. and Moreno-Alfonso, N. (2006) Power-Electronic Systems for the Grid Integration of Renewable Energy Sources: A Survey. IEEE Transactions on Industrial Electronics, 53, 1002-1016. http://dx.doi.org/10.1109/TIE.2006.878356

[15] Zeng, J.W., Qiao, W., Qu, L.Y. and Jiao, Y.P. (2014) An Isolated Multiport DC-DC Converter for Simultaneous Power Management of Multiple Different Renewable Energy Sources. IEEE Journal of Emerging and Selected Topics in Power Electronics, 2, 70-78.

[16] Bist, V. and Sing, B. (2013) An Adjustable-Speed PFC Bridgeless Buck-Boost Converter-Fed BLDC Motor Drive. IEEE Transactions on Industrial Electronics, 61, 2665-2677. http://dx.doi.org/10.1109/TIE.2013.2274424

[17] Abdin, E.S., Osheiba, A.M. and Khater, M.M. (1999) Modeling and Optimal Controllers Design for a Stand-Alone Photovoltaic-Diesel Generating Unit. IEEE Transactions on Energy Conversion, 14, 560-565. http://dx.doi.org/10.1109/60.790914

[18] Abdulhadi, M., Al-Ibrahim, A.M. and Virk, G.S. (2004) Neuro-Fuzzy Based Solar Cell Models. IEEE Transactions on Energy Conversion, 19, 619-624. http://dx.doi.org/10.1109/TEC.2004.827033

[19] Miyatake, M., Veerachary, M., Toriumi, F., Fujii, N. and Ko, H. (2011) Maximum Power Point Tracking of Multiple Photovoltaic Arrays: A PSO Approach. IEEE Transactions on Aerospace and Electronic Systems, 47, 367-380. http://dx.doi.org/10.1109/TAES.2011.5705681

[20] Brambilla, A., Gambarara, M., Garatti, A. and Ronchi, F. (1999) New Approach to Photovoltaic Arrays Maximum 
Power Point Tracking. The 30th Annual IEEE Power Electronics Specialists Conference, PESC'99, 2, 632-637. http://dx.doi.org/10.1109/pesc.1999.785575

[21] Abu-Rub, H., Iqbal, A. and Ahmed, S.M. (2012) Adaptive Neuro-Fuzzy Inference System-Based Maximum Power Point Tracking of Solar PV Modules for Fast Varying Solar Radiations. International Journal of Sustainable Energy, 31, 383-398.

[22] Gow, J.A. and Manning, C.D. (1999) Development of a Photovoltaic Array Model for Use in Power Electronics Simulation Study. IEEE Proceedings on Electrical Power Application, 146, 193-200. http://dx.doi.org/10.1049/ip-epa:19990116

[23] Al-Amoudi, A. and Zhang, L. (1998) Optimal Control of a Grid-Connected PV System for Maximum Power Point Tracking and Utility Power Factor. IEE PEVD98, Tarrytown, 21-23 September 1998, 325-330.

\section{Submit or recommend next manuscript to SCIRP and we will provide best service for you:}

Accepting pre-submission inquiries through Email, Facebook, Linkedin, Twitter, etc A wide selection of journals (inclusive of 9 subjects, more than 200 journals)

Providing a 24-hour high-quality service

User-friendly online submission system

Fair and swift peer-review system

Efficient typesetting and proofreading procedure

Display of the result of downloads and visits, as well as the number of cited articles

Maximum dissemination of your research work

Submit your manuscript at: http://papersubmission.scirp.org/ 